\title{
Rural Areas: The Real Home of the Nigerian Economy
}

\author{
Raji Abdullateef ${ }^{1} \&$ Muhammed Abubakar Yinusa $^{2} \&$ Mohmoh Musa Danjuma ${ }^{3}$ \\ Sulaiman Lanre Abdul-Rasheed ${ }^{4} \&$ Raji Abdulwasiu Adeyemi ${ }^{5}$ \\ ${ }^{1,2,3,4}$ Department of Sociology, Faculty of Social Sciences, University of Ilorin, Nigeria \\ ${ }^{5}$ School of International Studies, Universiti Utara Malaysia, Malaysia \\ Correspondence: Sulaiman Lanre Abdul-Rasheed, University of Ilorin, Nigeria. \\ Email: rasheed_sulaimon@yahoo.com
}

Received: August 18, $2017 \quad$ Accepted: September 23, $2017 \quad$ Online Published: October 1, 2017

doi:10.23918/ijsses.v4i2sip1

\begin{abstract}
The current troubles facing the Nigerian economy seem insurmountable. Should we speak of the current recession or the oil crash experienced in the international market? Should the case of oil-pipe vandalization as well as that of insurgency be breached? We could as well debate on the fall of the naira as against the US dollars and other recognized currencies in the international market. This could go on and on. It is as a consequence of this that this study tried to look at the central position of rural communities in finding lasting solutions to these economic woes. The utilitarian theory was employed in examining the phenomenon. The study revealed that rural areas can go a long way to advance the Nigerian economy if properly taken care of but if the current underuse of rural resources continues, the economy could be derailed. It is therefore recommended that renewed efforts should be made to explore the resources available in rural areas in order to tremendously increase the wealth of the nation as soon as possible.
\end{abstract}

Keywords: Rural, Economy, Home, Nigeria

\section{Introduction}

The economy of Nigeria has gone through so many ups and downs. There have been good and bad days for the country's economy as it has experienced best and worst days in its history. The history of the Nigerian economy dates back to 1960 where colonialism played a key role. The economy had so many prospects after independence from the British. The country had its earnings and incomes from taxes paid by foreign companies established by Europeans along its coast. These countries were established by trade posts by the Europeans. This was a period when slave trade was flourishing (Nigerian finder, n.d).

Nigeria was the world's largest exporter of groundnuts with almost $36 \%$ of the world groundnut trade. She was as well the second world's major cocoa exporter when she was delivering around $20 \%$ of the world cocoa trade. Her cotton seeds export represented almost $18 \%$ of world's cotton supply and Nigeria's share of the world's vegetable oil trade was around 11. Nigeria has an abundance of mineral resources that have considerable economic significance. They include coal, limestone, Columbite, gold, petroleum oil tin ore as well as natural gas while the potential raw materials that have not been commercially utilized zinc, iron ore, lead, wolfram china clay, and include lignite. Nigeria supplied almost 5 per cent of the world tin ore and was therefore the world's sixth producer of tin while 
Columbite, which is a by-product of tin, was also produced in large quantities accounting for about 95 per cent of total world supply (Ekundare, 1973).

Upon the discovery of crude oil and its ensuing exportation, the Nigerian economy experienced a boom as oil accounted for over $80 \%$ of the country's earnings in foreign exchange. This discovery helped the country's economy, but has turned out to be the bane of Nigeria's economic development. The fact being that, the income made from petroleum by the country made it abandon its agricultural sector (Ismail, 2010).

The Nigerian economy is a primary product oriented one and now dominated by the oil and gas sector. This sector is the core economic driver of the country, in terms of revenue generation, foreign exchange and foreign investments. The oil and gas sector accounts for over $90 \%$ of the Nigeria's exports and also about $80 \%$ of the country's budget revenues are based on earnings from the sector. The petroleum sector in 2011 accounted for 79 percent of federal income and 71 percent of revenue from exports (African Development Bank, 2013). Agriculture is also a dominant economic activity which accounted for about 40 percent of GDP in 2011 and employed around 70 percent of the Nigerian population. The labour force of the sector was valued to be 47.3 percent in 2009 and this increased to 58.8 percent in 2012 . Agriculture's share of exports was 75 percent in 1965 but declined to just 3 percent in 2012. Its contribution to GDP was about 63\% in 1960 but reduced to 34\% in 1988, 33.4 percent in 2009 and 30.9 percent in 2012 (Ignite, 2013).

When matters of diversification arise, the onus is largely on rural areas. Indeed, the prodigal son returns. There are abundant resources yet to be tapped in rural Nigeria. Apart from the obvious reserve of natural resources, there is also a wealth of potential tourist attraction centers that can be harnessed in the quest to uplift the nation from its current woes.

\section{Statement of Problem}

With the significance of the rural communities to the overall development of the Nigerian nation, its resources still remain untapped to its full potentiality with the nation still recovering from the drop in international price of crude oil. Not only is there a need to resort back to agriculture, the principle of diversification has to be embraced absolutely. Priorities need to be re-aligned. Considering the harsh economic realities the oil crises have shown, diversification is seen as a panacea for curing our ailed economy.

Despite the cries for diversification, areas of potentiality remain unexplored. In terms of natural resources, we have an awe-inspiring amount. These resources are overwhelmingly located in the rural parts of Nigeria. Majority of them have however not been harnessed. Should we talk of the reported untapped goldmines in Ebonyi and Osun State or the underwhelming mining of gemstones in Kaduna, Bauchi and Plateau States? This can go on and on but the picture has been depicted.

It is not that the government does not recognize the vast wealth of potentiality in the rural areasbut the little effort mustered towards fostering harnessing them has hit a brick wall. This, according to Smith (2008) has been linked to a number of problems faced by the Nigerian society such as corruption and mismanagement of funds. Nigeria has been described as a pathologically corrupt nation. This was backed up by the nation ranking 136 out of 175 in the Corruption Perception Index of 2016. Also, there 
is the lack of sufficient investors. This has been linked somewhat to the problem of insurgency in the nation. According to him, each administration that comes on board prescribes a new policy, especially on rural development, advocating an overhaul of the previous ones. As a consequence of this, the nation has toyed with a sizeable number of failed policies.

Also, on the issue of the naira devaluation, the role in which rural areas can play in the uplift of the currency from its current woes has been grossly overlooked. When effort is made to explore rural resources, sufficient foreign earnings can be obtained through exporting. This will eventually raise the value of the naira in the international market provided that a high Gross Domestic Product (GDP) is maintained

In addition, the exploration of rural resources, without care for the residing populace can result into cases of rebellion. Vivid examples are the Niger Delta Avengers, Movement for the Emancipation of Niger Delta, and so on. These sects claim to have reacted against the exploration of oil wells in their region by the Federal Government as a consequence of poor oil exploration practices. This had often resulted into oil spillage affecting the Niger Delta people both directly and indirectly. It affects them directly in the case of oil spillage in rivers compromising its purity. This could lead to hundreds of deaths. Indirectly, oil spillage in rivers could poison fishes, resulting in hunger as well as lack of game for fishermen. These fallouts lead to these sects vandalizing oil pipes, kidnapping workers as well as dignitaries, etc. In essence, rural areas are very important to the national economy.

\section{Objectives}

The paper tries to achieve the following objectives through the secondary data gathered:

1. To find out the causes and solutions to Nigeria's failing economy;

2. To ascertain the position of rural areas in the permanent development of the economy.

\section{Conceptual Framework}

Rural areas have been defined by various scholars. One of such definitions is the one given by The American Census Bureau which categorizes people who live in a place and having 2,500 people or less as rural while the Federal Statistics Office in Nigeria classifies a neighborhood that has a population of 20,000 people or less as rural. Afolayan (1995) identified rural areas by criteria such as low infrastructural development level i.e. roads, little or no water supply, insufficient or no electricity among others. Ele (2006) also defined rural areas as the opposite of urban areas whose population mainly engages in agriculture as well as the basic rudiment of tertiary activities.

\section{Rural Areas: Home for Nigerian Fortune}

Rural areas have from time immemorial been homes for the economy of Nigeria but the country has failed to develop these areas that have made it relevant in the world economy. Nyagba (2009) made it known that the most crucial sector of the Nigerian residents is the rural communities due to the fact that they form a principal source of capital for the country and they also form a major source of raw materials for industrial processes. This was also supported by Abah (2010) who noted that rural people have 
always been known to source their income from in economic activities like agriculture which constitutes the bedrock of Nigeria's economic development.

Below is a detailed discussion of how rural areas have been useful and important to Nigeria.

- Rural communities are the food and fiber producers of the society: Even in developed societies, farm produce still serve as the basis for the manufactured foods even though they have managed to develop synthetic food items successfully. Farming is the fabric of rural society and is the major economic activity in many Nigerian rural sector. Almost $90 \%$ of the country's food is made by farmers who engage in small-scale farming on undersized lands and rely solely on rainwater instead of an irrigation system (IFAD, 2014).

- Almost all natural resources that make up nation's wealth are extracted from rural areas: Advancement in agriculture is germane for the improvement in supply of raw materials for the agro-based industries particularly in our developing country. Flour mills, rice shelters, bread, milk products, oil and similar mills, meat, wineries, leather mills textile among other industries are based majorly on agricultural products which makes rural areas the home for natural resources (Ippmedia, 2017).

- In Nigeria, a large number of people reside in rural areas and obtain their source of revenue from there: According to the World Bank collection of development indicators in 2015, rural population in Nigeria was reported at $52.22 \%$. Nigeria's poor rural inhabitants rely largely on farming for food and earnings. However, poverty is rigorous in these communities where about 80 percent of the residents still live in abject poverty with limited infrastructural and social facilities (IFAD, 2014). This alarming rate of poverty therefore calls for development of these rural areas.

- Rural areas lay the foundation for national development due to their provision of human resources for urban areas: Fertility rate in rural areas has always been higher than those of their urban counterparts. Studies have time and again revealed that rural residents usually feel the need to have greater number of children than urban area dwellers. For instance, studies by Nepal Demographic and Health Survey, 2003 showed that fertility rate for rural women are considerably higher compared to their urban counterpart. Averagely, rural woman usually produce one more child in their productive years (giving birth to an average of 6.1) than women in urban areas (4.9 on the average). Thus, the additional population in rural areas supplies the needed manpower in urban areas.

- In times of urban crises, rural areas function as places of shelter to people: Rural people are relatively unaffected by the violence which is prevalent among the diverse urban population. This is evidenced by the various violent acts that are experienced by people in Nigerian cities which make some of them seek refuge in their respective villages.

- Ruralites have certain culture of conservatism which makes rural area the best place for preservation of culture and tradition: Most rural communities have rich historical heritages that are of importance to the nation and these are at the risk of being lost in the urban areas due mainly to their heterogeneous nature (Rural Regeneration, 2012). 
From the above discussion, it is obvious that the argument on rural areas being the real homes of the Nigerian economy as at this present time is not debatable. Thus, there is the need for sustainable development in the rural sector in order to uplift the nation from its current economic struggles.

\section{Challenges Facing Rural Areas}

There are many challenges facing rural areas in Nigeria which serve as obstacles to national development, ranging from the obvious shortage of basic infrastructural facilities to the generally low living standard among the ruralites. Nwuke, (2004) observed that poverty is pervasive among the ruralites because about $70 \%$ of the Nigerian people who still live in abject poverty are resident in rural areas. Abah (2010) also stated that rural communities in the country are characterized by poor housing conditions and all sorts of political and social isolation.

Rural areas in Nigeria are also dominated by defective road networks and the condition is even made worse as the landscape of several rural areas are made up of hills and valleys and other challenges in the environment like swampy and clayey areas. It therefore brings huge difficulty in the road construction (Olayiwole \& Adeleye, 2005). Ele (2006) also noted that there is the challenge of transportation in rural areas as many rural roads are inaccessible and bridges that link these roads to other areas are ramshackle. In some areas, these bridges do even exist.

Poor educational system is also apparent in nearly all rural areas in Nigeria. This makes it difficult for rural areas to compete with their urban counterparts and contribute meaningfully to the nation's development. Ijere (1992) noted in this respect that education in rural areas is marred by inadequate functional facilities and disregard for technical and handicraft subjects. Okoli and Onah (2002) also reiterated that education which is thought to be a right of every child in Nigeria has become a delusion to majority of poor rural inhabitants.

There is equally shortage of modern health institutions in Nigerian rural areas because there are barely well-resourced health centers, clinics, maternal homes and hospitals. Okoli and Onah (2002) noted in the same way that medical institution of any type are barely present in most Nigerian rural areas. Where this institution exists, people will have to journey lengthy distances to access them. Furthermore, there is clearly inadequate supply of clean water in the Nigerian rural areas. This is enhanced by the circulation of diseases that are water-borne and worsened by poor sanitation (Ele, 2006).

In summary, Ijere (1992) stated that it is disheartening that the rural sector of Nigeria which accounts for about $95 \%$ of the country's food supply has been persistently associated with poverty alongside other features of underdevelopment like poor living standard which stems from lack of or inadequate basic amenities like drinkable water, good roads, functional educational facilities, electricity, basic health care facilities, essential agricultural services such as storage facilities, irrigation as well as other farm needs like industrial centers for development of rural industrialization, skills acquisition centers for manpower and skills improvement, fertilizer for improved agricultural activities, improved market, commerce to boost activities in rural economy and the incomes that come along. 


\section{Rural Development Programs in Nigeria since Independence and Why They Have Not Worked}

According to Samson and Augustine (2014), various attempts have been made by successive administrations in Nigeria which are directed towards reducing poverty and development of rural areas; the methods have often been shaped by the meaning these governments give to rural development. Prominent among these programs as he noted are as follows:

- 1972-National Accelerated Food Production Program and the Nigeria Agricultural and Cooperative Bank,

- 1976-Operation Feed the Nation: which sought to enlighten farmers in rural areas on how to make use modern farming equipment,

- 1979-Green Revolution Program: to reduce food importation and increase local food production,

- 1986-Directorate of Food, Roads and Rural Infrastructure (DFFRI),

- 1987-National Directorate of Employment (NDE),

- 1993-Family Support program and the Family Economic Advancement Program,

- 2001-National Poverty Eradication Program (NAPEP): This was created to substitute the Poverty Alleviation Program that had previously failed, and

- 2004-National Economic Empowerments and Development Strategy. (NEEDS): This was created to accomplish reduction in poverty with the aid of employment generation, creation of wealth and value re-orientation.

Others include: Integrated Community Development Project, The 7 point Agenda, 2007, State Economic Empowerment and Development Strategy (SEEDs), The Nigerian Incentive-Based Risk-sharing System for Agricultural Lending (NIRSAL), 2010, Local Economic Empowerment and Development Strategy (LEEDs), Growth Enhancement Scheme (GES), 2011, The Rural Finance Institution Building Programme (RUFFIN), 2011, The Agricultural Resilience in Nigeria (ACARN), 2013, The Green Alternative (an Agricultural promotion policy), 2016 (Federal Ministry of Agriculture and Rural Development, 2016).

However, these developmental plans seem not to have seen the light of the day in terms of achieving their targeted aims based on the following according to Coker and Obo (2012):

1. Lack of necessary human resources to administer the various agencies that are created for the implementation of rural development in Nigeria.

2. Insufficient funds also contribute to these challenges as many of these agencies created are not sufficiently funded. Even when funds are planned for, those who are to implement them often do not have access to them. A huge portion of these funds are usually redirected into personal purses.

3. The landscape of many rural areas poses challenges for projects execution. For instance, it is expensive and difficult to construct or even repair some rural roads effectively due to rocky and swampy land.

4. Local Governments have failed to operate as agents of transformation in rural. Local Governments In 1976 were established to foster the fast development of the Nigerian rural economy along with other functions. It has however been shown through experiences that many local governments have been unsuccessful in doing that. This is partly due to the fact that people 
who are not permanent residents of the local government areas are either elected or appointed into local government Councils, therefore these people unfamiliar with the present states of the locality they rule over.

5. Wrong channel of communication to get to the intended population. This is inherent in the example of the National Orientation Agency which adopts the use of Newspapers, Television, and Radio as her core media to pass information to the rural inhabitants. This however had little impact on the people in rural areas due to high illiteracy rate as well as ineffective or inadequate amenities such as electricity which they can use to power the television or radio sets.

\section{Theoretical Framework}

The utilitarian theory is used in the course of this study. Utilitarianism represents an ethical theory which states that the optimum action is that which maximizes utility. "Utility" in this sense can be seen in various ways commonly in terms of well-being of the involved entities. Jeremy Bentham is the father of utilitarianism. He described utility as the sum total of all pleasure that is consequent of an action, without the anguish of anyone involved in the action. Bentham (2001) posited that the consequences of an action are the only standard of right and wrong. Utilitarianism basically considers all interests equally.

Mill (2011) has as well contributed to the theory of utilitarianism. According to him, the word utility means people carrying out actions for the purpose of social utility. To him, social utility depicts the welfare of numerous people. Therefore, an action that turns out to be the greatest pleasure for the utility of society is the preeminent action.

Therefore, rural areas having the necessary resources needed to drive development in Nigeria, possessing the power to make or mar development in the nation should be explored in order to reap the fruits of development. In the process of achieving this, the principle of social utility should be kept in mind. That is, the ruralites should be inclusive of the developmental efforts. This could prevent future agitations against perceived exploitation by various groups in Nigeria. No region should be segregated in deriving benefits reaped from their environment. It has been previously established that all efforts in fostering development must take the rural areas into cognizance. It is therefore rational and of the greatest utility to make use of the wealth of resources available in the rural areas for the happiness of all. The exploration of the rural resources would be of benefit to the nation. On the issue of inflation and the devaluation, harnessing these resources would stabilize the economy, causing a series of chain reactions that will benefit the common man.

\section{Conclusion and Recommendations}

Based on the secondary data consulted in the course of this study, it can be seen that previous national developmental efforts have not exactly been a roaring success. This is largely a consequence of the failure to passionately explore the cornucopia of resources readily available in the rural areas. Nigeria has been blessed with these resources and it is nothing short of blatant irrationality not to make use of them in uplifting the nation from its current woes. In line with this, it is recommended that future plans to cure the economy of its current anguish should strategically explore the wealth of resources available. Apart from natural resources, Nigeria is a nation whose cultural lushness is simply undeniable. Stemming from this, bounties can be made from showcasing our culture to the outside world in its 
entirety. By showcasing the richness of our culture, the balance of trade can be rectified in our favor. Aside from these, there are potential tourist attraction centers scattered all over the country. Efforts should be made to harness their potentiality. All these combined should lift the nation from its economic troubles. Indeed, rural areas are forever intricately tied with national development.

\section{References}

Abah, N. (2010). Development Administration: A Multi-Dispensary Approach. Enugu: John Jacob Classic Publishers.

Afolayan, S. O. (1995). Community mobilization for rural development in Bangladesh: Lessons for Nigeria. Ilorin: Agricultural and Rural Management Training Institute, ARMTI

African Development Bank (2013). Country Strategy Paper 2013-2017. African Development Bank

Bentham, J. (2001). The Works of Jeremy Bentham. (Vol 2). Boston: Adamant Media Corporation.

Coker, M. A., \& Obo, U. B. (2012). Problems and prospects of implementing rural transformation programmes in Odukpani local government area of Cross-River state, Nigeria. World J Young Researchers, 2(2), 26.

Ekong, E. E. (2011). Introduction to Rural Sociology. Uyo: Dove Publishers.

Ekundare, R. A. (1973). An Economic History of Nigeria I860-1960. London: Methuen \& Co Ltd

Ele, C. (2006). Evangelization through Rural Development. Nsukka: Great AP Publishers Ltd.

Federal Ministry of Agriculture and Rural Development (2016).The Agriculture Promotion Policy (2016-2020)- Building on the successes of the ATA, closing key gaps. Abuja: Federal Ministry of Agriculture and Rural Development.

Ignite, (2013). Fiscal Management Reform Gaining Traction in Nigeria Again.

Ijere, M. (1992). Leading Issues in Rural Development. Enugu: Acena Ventures.

Ikelegbe, A. (2006). Public Policy Analysis: Concepts, Issues and Analysis. Lagos: Imprint Services.

Ippmedia (2017). Importance of agricultural sector in a country's economy. Retrieved from www. Ippmedia.com

Ismail, A. A (2010). Nigeria:Economy monopolization. Retrieved from Gamji.com/articles5000/news52 43.htm

Mill, J. S. (2011). A System of Logic, Ratiocinative and Inductive (Classic Reprint). Oxford: Oxford University Press

Nigerian finder (n.d.). History of Nigerian Economy: A brief overview. Retrieved from http://nigerianfinder.com/history-of-nigerian-economy-a-brief-overview/

Nwuke, K. (2004). Poverty reduction strategies towards the millennium development goals: Africa's experiences and lessons for Nigeria. Paper delivered at the Enugu policy forum organized by African Institute for Applied Economics, Enugu.

Nyagba, S. (2009). Review of Nigeria's rural development policy for sustainable development. Paper presented at Business Round Table at Abuja, 9 - 11 July.

Okoli, F., \& Onah, F. (2002). Public Administration in Nigeria: Nature, Principles and Application. Enugu: John Jacobs Publishers Ltd.

Olayiwola, L.M., \& Adeleye, O.A. (2005). Rural infrastructural development in Nigeria: Between 1960 and 1990- problems and challenges. Journal of Social Science, 11(2), 91-95

IFAD (2014). Rural poverty in Nigeria. IFAD. Retrieved from http://www.ruralpovertyportal.org/web/ Rural-poverty-portal/country/home/tags/nigeria

Rural Regeneration (2012). Importance of conservation of the rural areas. Retrieved from http://www.ruralregenerationzone.co.uk/importance-of-conservation-of-the-rural-areas.html

Samson, E., \& Augustine, I. (2014). The nigerian economy reforms, emerging trends and prospects. Benin City: Centre for Population and Environmental Development (CPED).

Smith, D.J (2008). A Culture of Corruption: Everyday Deception and Popular Discontent in Nigeria. 
International Journal of Social Sciences \& Educational Studies ISSN 2520-0968 (Online), ISSN 2409-1294 (Print), October 2017, Vol.4, No.2 (Special Issue)

Princeton: Princeton University Press

Yekeen, M. (April 16, 2016). Ten major untapped resources in Nigeria. Economic Confidential 